\title{
Association between CRP genetic diversity and bipolar disorder comorbid complications
}

\author{
Wahid Boukouaci ${ }^{1 \dagger}$, José Oliveira ${ }^{1,2 \dagger}$, Bruno Etain ${ }^{2,3,4,5}$, Meriem Bennabi ${ }^{1,2}$, Christina Mariaselvam , \\ Nora Hamdani ${ }^{2,6,7,8}$, Céline Manier' ${ }^{1}$, Djaouida Bengoufa9 ${ }^{9}$ Frank Bellivier ${ }^{2,3,4,5}$, Chantal Henry ${ }^{2,6,7,8}$, \\ Jean-Pierre Kahn ${ }^{2,10}$, Dominique Charron ${ }^{1,2}$, Rajagopal Krishnamoorthy ${ }^{1,2}$, Marion Leboyer 2,6,7,8 \\ and Ryad Tamouza $1,2,5,9^{*} \neq$
}

\begin{abstract}
Background: Chronic low-grade inflammation is believed to contribute, at least in a subset of patients, to the development of bipolar disorder (BD). In this context, the most investigated biological marker is the acute phase response molecule, C-reactive protein (CRP). While the genetic diversity of CRP was amply studied in various pathological settings, little is known in BD.

Methods: $568 \mathrm{BD}$ patients along with 163 healthy controls $(\mathrm{HC})$ were genotyped for the following single-nucleotide polymorphisms (SNPs) on the CRP gene: intron rs1417938 (+ 29) T/A, 3'-UTR rs1130864 (+ 1444) G/A, and downstream rs1205 (+ 1846) (C/T). The statistical analysis was performed using Chi-square testing and consisted of comparisons of allele/genotype frequencies between patients and controls and within patient sub-groups according to $\mathrm{BD}$ clinical phenotypes and the presence of thyroid disorders.

Results: We found that the frequencies of the studied SNPs were similar in BD and HC groups. However, the CRP rs 1130864 A allele carrier state was significantly more frequent: (i) in BD patients with thyroid disorders than in those without ( $p c=0.046$ ), especially among females $(p c=0.01)$ and independently of lithium treatment, (ii) in BD patients with rapid cycling than in those without $(p c=0.004)$.

Conclusions: Overall, our findings suggest the possibility that CRP genetic diversity may contribute to the development of auto-immune comorbid disorders and rapid cycling, both proxy of BD severity. Such findings, if replicated, may allow to predict complex clinical presentations of the disease, a possible step towards precision medicine in psychiatry.
\end{abstract}

Keywords: Bipolar disorder, CRP, Polymorphisms, Early-onset bipolar disorder, Autoimmune thyroiditis, Rapid cycling

\section{Background}

There is ample evidence for a dysregulated immune/ inflammatory component in major psychiatric disorders such as bipolar disorder (BD) (Berk et al. 2013; Leboyer et al. 2016) and schizophrenia (Kirkpatrick and Miller

*Correspondence: tamouza.ryad@gmail.com

†Wahid Boukouaci and José Oliveira are co-first authors

${ }^{\ddagger}$ Marion Leboyer and Ryad Tamouza are co-senior authors

1 INSERM, U1160, Hôpital Saint Louis, 75010 Paris, France

Full list of author information is available at the end of the article
2013). Such immune dysfunction is reflected, at least in sub-groups of patients, by an underlying chronic lowgrade inflammation characterized by increased circulating levels of pro-inflammatory molecules along with an elevated incidence of comorbid inflammatory medical conditions viz cardiovascular/metabolic and autoimmune disorders (Benros et al. 2014; Rosenblat and McIntyre 2015).

Among the markers of inflammation, elevated levels of C-reactive protein (CRP), a component of the innate immune system and an acute phase reactant, are 
a consistent finding in these disorders (Dickerson et al. 2007; Ford and Erlinger 2004; Huang and Lin 2007; Liukkonen et al. 2006). We recently extended this notion through a meta-analysis showing that CRP levels are elevated in patients with $\mathrm{BD}$, particularly during manic episodes and euthymic phases (Dargél et al. 2015). Interestingly, CRP level is also an independent risk factor for cardiovascular/metabolic and autoimmune disorders including autoimmune thyroiditis, a prominent comorbidity of BD (Chakrabarti 2011). Also striking is the observation that CRP levels decrease from pre-treatment levels in a significant proportion of BD patients under lithium monotherapy, as if lithium was also acting on inflammation either directly or indirectly (Hornig et al. 1998). However, despite the reported plausible role of lithium on immune-modulation associated with potential antioxidant effects, it is still debated if the normalized values of inflammation markers in euthymic BD patients under lithium are due to a direct effect on immune-modulation or an indirect effect due to symptom stabilization (van den Ameele et al. 2016; Data-Franco et al. 2017).

The CRP molecule is produced by the liver in response to pro-inflammatory stimuli, induced either by infection, cellular stress or tissue damage (Eklund 2009). When released in the circulation, CRP activates the classical complement pathway, a key player of various pivotal innate immune processes such as inflammation and phagocytosis (Gershov et al. 2000). Moreover, the complement system has also been shown to be involved in neurogenesis and pruning of synapses in the central nervous system providing hence another link between CRP and mental/neurological physiopathology (Pekny et al. 2007; Rahpeymai et al. 2006).

Systemic basal circulating CRP levels are genetically determined and influenced by a number of loci including CRP gene variants per se in various ethnic groups (Martínez-Calatrava et al. 2007; Reiner et al. 2012). In this context, a meta-analysis of genome-wide association studies of over 80,000 subjects for CRP level variability allowed to identify 18 loci among which five (that include the $C R P$ gene) had been known to play a role in innate and adaptive immune response pathways (Dehghan et al. 2011). Interestingly, six other loci associated with CRP levels in that study were involved in metabolic regulation of diabetes mellitus. It has been also showed that some $C R P$ variants are associated with raised levels of serum CRP while others with decreased ones (Guo et al. 2014; Kong et al. 2012; Miller et al. 2005; Ottaviani et al. 2011; Russell et al. 2004).

Given the potential influence of circulating CRP on neuropsychiatric comorbidities, neurogenesis and synaptic pruning, it is important to explore the genetics of CRP in these situations (going beyond the simple assessment of CRP level) and to relate its potential role in susceptibility to these disorders and/or to comorbid conditions. Indeed, reports on the influence of CRP genetic variants in mental disorders are quite limited and essentially related to depression (Bufalino et al. 2013; Halder et al. 2010).

Since immune dysfunction and auto-immunity are prominent in $\mathrm{BD}$, it is of particular interest to assess the CRP genetics in its context. Towards this end, we explored here the genetic diversity of $C R P$ in a large French Caucasian patient cohort affected by BD with or without comorbid presentation.

\section{Methods}

\section{Sample composition}

Five hundred and sixty-eight BD outpatients, followed in three French university-affiliated psychiatry departments (Paris-Créteil, Bordeaux and Nancy), were interviewed by expert psychiatrists using the French version of the Diagnostic Interview for Genetic Studies (DIGS version 3.0) (Nurnberger et al. 1994). Those satisfying the Diagnostic and Statistical Manual for Mental Disorders (DSM)-IV criteria (American Psychiatric Association 1994) for type I or II or not otherwise specified (NOS) $\mathrm{BD}$ were included in the present study. At inclusion, all were found to be euthymic with a Montgomery-Asberg Depression Rating Scale score and a Bech-Rafaelsen Mania Rating Scale score not exceeding five (Bech et al. 1978; Montgomery and Asberg 1979). A set of demographic/clinical variables including, presence of a thyroid disorder, age at onset (AAO) and rapid cycling (both proxy of disease complexity) were recorded (Table 1).

One hundred and sixty-three healthy controls $(\mathrm{HC})$, assessed using the National Institute for Mental Health Family Interview for Genetic Studies and DIGS for personal and family history of psychiatric disorders, were also recruited (Maxwell 1992). Inclusion criteria were based on the absence of personal or family history (first degree) of psychiatric disorders, affective disorders or suicidal behavior. Consecutive recruitment of patients and controls (all of French descent with at least three grandparents from the mainland of France) extended between February 2006 and January 2010. The age at onset (AAO) threshold (22 years) of $\mathrm{BD}$ corresponding to that at which the first mood episode (depressive, manic, hypomanic or mixed) occurred was defined as previously reported (Geoffroy et al. 2013) and were categorized into two sub-groups i.e., early and late (Oliveira et al. 2014). Rapid cycling status was defined (according to DSM-IV), as the occurrence of at least four major depressive, manic, hypomanic, or mixed episodes during the previous year and thyroid disorders were objectivized by routine standard biological testing. Following institutional ethical committee 
Table 1 Demographic and clinical characteristics of study subjects

\begin{tabular}{|c|c|c|c|}
\hline & $\mathrm{BD}(n=568)$ & $\mathrm{HC}(n=163)$ & $p$ value \\
\hline & Mean \pm SD & Mean \pm SD & \\
\hline \multirow[t]{3}{*}{ Age at inclusion } & $42.4 \pm 13.1$ & $41.2 \pm 11.6$ & NS \\
\hline & $\mathrm{BD}(n=568)$ & $\mathrm{HC}(n=163)$ & $p$ value \\
\hline & $n(\%)$ & $n(\%)$ & \\
\hline \multicolumn{4}{|l|}{ Gender } \\
\hline Male & $236(41.5)$ & $100(61.3)$ & $p<0.05$ \\
\hline Female & $332(58.5)$ & $63(38.7)$ & \\
\hline \multicolumn{4}{|l|}{ Age at onset ${ }^{\mathrm{a}}$} \\
\hline Early-onset (< 22 years) & $253(47.5)$ & - & \\
\hline Late-onset ( $\geq 22$ years) & $280(52.5)$ & - & \\
\hline \multicolumn{4}{|l|}{ Thyroiditis $^{\mathrm{a}}$} \\
\hline No & $433(84.7)$ & - & \\
\hline Yes & $78(15.3)$ & - & \\
\hline \multicolumn{4}{|l|}{ Rapid cycling ${ }^{\mathrm{a}}$} \\
\hline No & $435(86.1)$ & - & \\
\hline Yes & 70 (13.9) & - & \\
\hline
\end{tabular}

$B D$ bipolar disorder, $H C$ healthy controls, $S D$ standard deviation, NS non-significant

a Data not available for all patients

approval and guidelines of the research protocol, written informed consent was obtained from all participating subjects. The present study forms part of a much larger ongoing National (French) program since 2014 and entitled "Genetic and environmental susceptibility factors to bipolar disorders" (RBM0436 and C0829). The national program had previously been approved by the French medical ethics committee (Comité de Protection des Personnes (CPP) IDRCB2008_AO1465_50 VI-Pitié Salpetrière 11808 ) and carried out according to the approved guidelines.

\section{CRP genotyping}

Genomic DNA was extracted from EDTA-treated peripheral blood samples or B-lymphoblastoid cell lines using the Nucleon BACC3 kit (GE HealthCare, Chalfont St Giles, UK). Three single-nucleotide polymorphisms (SNPs) on the CRP gene, namely intron $r s 1417938$ $(+29)$ T/A, 3'-UTR $r s 1130864$ (+ 1444) G/A and further downstream $r s 1205(+1846)(\mathrm{C} / \mathrm{T})$ were analyzed by a TaqMan $^{\circledR} 5^{\prime}$-nuclease assay (Applied Biosystems ${ }^{\circledR}$, Foster city, CA, USA) with allele-specific fluorogenic oligonucleotide probes. The following pre-developed TaqMan ${ }^{\circledR}$ assay genotyping kits were used: C_7479322_10, C_7479332_10 and C_7479334_10.

\section{Statistical analysis}

Comparisons of genotype and allele frequencies between patients and controls were performed using the Chisquare testing. The $p$ values (two tailed) were corrected $(p c)$ using the Bonferroni method and findings were considered statistically significant for $p c<0.05$. Both odds ratio (OR) and confidence interval 95\% (CI 95\%) were calculated to assess the relative risk conferred by a specific allele or genotype. The demographic/clinical items viz AAO, lifetime presence of thyroid disorders (analyzed according to lithium intake or not) and rapid cycling were included in the analysis. Deviation, if any, from the Hardy-Weinberg equilibrium was analyzed using the Chi-square test. Pairwise linkage disequilibrium (LD) was ascertained using the Linkage Disequilibrium Analyzer 1.0 software (Ding et al. 2003). Association analyses were performed using SPSS for Windows, Version 16.0.

\section{Results}

Demographic and clinical characteristics of study subjects are described in Table 1 . The proportion of female gender was significantly higher in patients $(58.5 \%)$ than in controls (38.7\%). The observed genotype distribution satisfied the expected Hardy-Weinberg proportions for both patient and control samples and the overall frequencies were comparable to those previously published in a public database (http://www.ncbi.nlm.nih.gov/).

Both CRP rs1130864 and rs1417938 polymorphisms were in complete linkage disequilibrium (LD) in our study subjects and hence only CRP rs1130864 and $r s 1205$ polymorphisms (the latter not in LD with the former) were taken into consideration in further analyses. No difference was noted in the distribution of these two SNPs 
between patients and controls even after gender stratification (data not shown).

Analysis of the distribution of CRP genotypes revealed that the CRP rs 1130864 A allele carrier state (homozygous and compound heterozygous combination) was significantly more frequent in $\mathrm{BD}$ patients with thyroid disorders than in those without ( $r s 1130864$ AA + AG vs. GG others: $64.1 \%$ vs $50.1 \%, p=0.023, p c=0.046$; OR $=1.78$, $95 \% \mathrm{CI}=1.08-2.96)$, the difference relatively more pronounced among females ( $r s 1130864$ AA + AG vs. GG: $69.6 \%$ vs $50.4 \%, p=0.005, p c=0.01$; OR $=2.25,95 \%$ $\mathrm{CI}=1.27-4.04$ in female patients, respectively, with and without thyroiditis) (Table 2). No statistically significant results were found when stratifying patients accounting for AAO. The analysis of the potential impact of lithium intake did not reveal any difference in the genotype distribution between patients with and without thyroiditis and this was also regardless of the gender (data not shown). Similarly, we also found that the CRP rs1130864 A allele carrier state was significantly more frequent in $\mathrm{BD}$ patients with rapid cycling than in those without ( $r s 1130864$ AA + AG vs. GG others: $68.6 \%$ vs $49.0 \%, p=0.002, p c=0.004$; $\mathrm{OR}=2.27,95 \% \mathrm{CI}=1.33-3.95$, respectively, in patients with and without rapid cycling) (Table 2).

\section{Discussion}

BD is now clearly considered as being a multisystem disorder given the elevated burden of medical comorbidities, including cardiovascular disorders, diabetes

Table 2 CRP rs1130864 genotype distribution in bipolar disorder patients with and without thyroid disorders

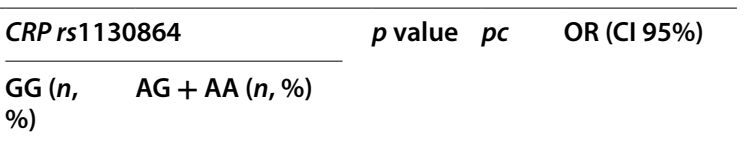

\begin{tabular}{|c|c|c|c|c|c|}
\hline \multicolumn{6}{|c|}{ Thyroiditis } \\
\hline Yes & $28(35.9)$ & $\begin{array}{l}38(48.7)+12 \\
\quad(15.4)\end{array}$ & 0.023 & 0.046 & $1.78(1.08-2.96)$ \\
\hline No & $216(49.9)$ & $\begin{array}{l}178(41.1)+39 \\
\quad(9.0)\end{array}$ & & & \\
\hline \multicolumn{6}{|c|}{ Female patients } \\
\hline Yes & $21(30.4)$ & $\begin{array}{l}36(52.2)+12 \\
\quad(17.4)\end{array}$ & 0.005 & 0.01 & $2.25(1.27-4.04)$ \\
\hline No & $112(49.6)$ & $94(41.6)+20(8.8)$ & & & \\
\hline \multicolumn{6}{|c|}{ Early-onset BD } \\
\hline Yes & $11(34.4)$ & $16(50.0)+5(15.6)$ & NS & NS & $1.89(0.87-4.25)$ \\
\hline No & $104(49.8)$ & $89(42.6)+16(7.7)$ & & & \\
\hline \multicolumn{6}{|c|}{ Rapid cycling } \\
\hline Yes & $22(31.4)$ & $\begin{array}{l}34(48.6)+14 \\
\quad(20.0)\end{array}$ & 0.002 & 0.004 & $2.27(1.33-3.95)$ \\
\hline No & $222(51.0)$ & $\begin{array}{l}176(40.5)+37 \\
\quad(8.5)\end{array}$ & & & \\
\hline
\end{tabular}

CRP C-reactive protein, $O R$ odds ratio, $C l$ confidence interval mellitus, obesity and auto-immune disorders, the majority of them likely related to the often observed immune dysfunction (Leboyer et al. 2012). According to the dual implication of CRP molecules in both acute and chronic inflammatory processes (Black et al. 2004) and given the known genetic control governing their production, we investigated here the distribution of three CRP SNPs namely $r s 1417938, r s 1130864$, and $r s 1205$, all having functional relevance in terms of CRP expression as suggested by previous studies (Halder et al. 2010; Ottaviani et al. 2011; Zacho et al. 2008; Zakharyan et al. 2010).

The observed absence of association in the whole sample studied here might be explained either by the relatively small sample size and/or by the well-known clinical heterogeneity characterizing BD. Merely, as BD could semantically be compared to an "umbrella" covering several disorders governed by specific mechanisms, the genetic association observed herein with sub-forms of the disorder may possibly reflect different operating immunological processes. Nevertheless, lack of association in case-control analyses is in agreement with previous studies exploring the genetics of CRP production in $\mathrm{BD}$ and other psychiatric diagnoses using much larger sample sizes (Avramopoulos et al. 2015; Prins et al. 2016).

When analyzing patients with thyroid disorders, we found that BD male and female patients differed in terms of SNPs distribution, a notion already attributed to differences in hormonal, behavioral, and lifestyle factors in the context of the disorder (Hillegers et al. 2007; Hornig et al. 1998; Kupka et al. 2002). In particular, the prevalence of thyroid-related disorders, namely the autoimmune ones, is known to be much higher in females than in males (Bauer et al. 2014; Özerdem et al. 2014). This may explain why we observed that the $3^{\prime}$-UTR CRP rs1130864 A minor allele carrier state is associated with autoimmune thyroiditis stringently in female patients.

In addition, we also found that such association is independent of lithium treatment, a finding in agreement with previous reports showing that autoimmune thyroiditis is a comorbid condition occurring independently of lithium uptake (Kupka et al. 2002; Padmos et al. 2004). Since CRP levels tend to decrease in BD patients on lithium monotherapy, lithium treatment would be expected to mask the elevated levels of CRP in thyroid disorders, if the analysis were to be based solely on the serum CRP levels (Hornig et al. 1998). We also show that the $3^{\prime}$-UTR CRP rs1130864 A allele carrier state is more prevalent among patients with rapid cycling, which is relevant since thyroid disorders and auto-immune abnormalities are associated with refractory forms of BD, in particular, rapid cycling (Chakrabarti 2011; Padmos et al. 2004), even though these two phenotypes were not correlated in our cohort. 
Although our results warrant replication, it is of interest to hypothesize that a subgroup of BD patients is associated with CRP gene variants, namely female patients having thyroid disorders and/or rapid cycling suggesting that abnormal inflammatory processes may be a link between these apparently distinct clinical features.

\section{Conclusions}

To confirm the role of CRP, our findings need to be replicated in a larger sample along with available levels of circulating serum levels of CRP. Within the field of "immunopsychiatry" attempts to identify meaningful subforms of BD, relevant to specific underlying mechanisms may lead to specific innovative therapeutic strategies.

\section{Abbreviations \\ BD: bipolar disorder; CRP: C-reactive protein; DIGS: Diagnostic Interview for Genetic Studies; DSM-IV: Diagnostic and Statistical Manual for Mental Disor- ders (DSM)-IV; NOS: not otherwise specified; HC: healthy controls; SNP: single- nucleotide polymorphism; LD: linkage disequilibrium; 3'-UTR: $3^{\prime}$ untranslated region.}

\section{Authors' contributions \\ WB, JO, DC, RK, ML, and RT coordinated the study and wrote the manuscript. $M B, C M, D B, C M$ participated to the experimental work and to the statisti- cal analyses. NH, BE, FB, CH, and JPK coordinated patients' inclusion. WB, JO, $\mathrm{ML}$, and RT finalized the manuscript. All authors read and approved the final manuscript.}

\section{Author details}

${ }^{1}$ INSERM, U1 160, Hôpital Saint Louis, 75010 Paris, France. ${ }^{2}$ Fondation FondaMental, 94000 Créteil, France. ${ }^{3}$ AP-HP, Département de psychiatrie et de medicine addictologique, Hôpital Fernand Widal, Paris, France. ${ }^{4}$ INSERM, UMR-S1144-VariaPsy, Hôpital Fernand Widal, 75010 Paris, France. ${ }^{5}$ Université Paris Diderot, Sorbonne Paris-Cité, 75013 Paris, France. ${ }^{6}$ INSERM, U955, Psychiatrie Translationnelle, 94000 Créteil, France. ${ }^{7}$ Faculté de Médecine, Université Paris-Est, 94000 Créteil, France. ${ }^{8}$ AP-HP, DHU PePSY, Pôle de Psychiatrie, Hôpitaux Universitaires Henri Mondor, 94000 Créteil, France. ${ }^{9}$ Laboratoire Jean Dausset and LabEx Transplantex, Hôpital Saint Louis, 75010 Paris, France.

${ }^{10}$ Service de Psychiatrie et Psychologie Clinique, CHU de Nancy, Hôpitaux de Brabois, 54500 Vandoeuvre Les Nancy, France.

\section{Acknowledgements}

We thank patients with bipolar disorders and controls who agreed to participate in this study. We thank the Cochin Hospital cell repository, the Clinical Centre of Investigations, the Biological Resources Centre) of Mondor Hospital, and the blood bank Centre of EFS Créteil for technical assistance. We thank the FondaMental Foundation.

\section{Competing interests}

The authors declare that they have no competing interests.

\section{Availability of data and materials}

Data and material are available upon demand to the authors.

\section{Ethics approval and consent to participate}

Following institutional ethical committee approval and guidelines of the research protocol, written informed consent was obtained from all participating subjects. The present study forms part of a much larger ongoing National (French) program since 2014 and entitled "Genetic and environmental susceptibility factors to bipolar disorders" (RBM0436 and C0829) The national program had previously been approved by the French medical ethics committee (Comité de Protection des Personnes (CPP) IDRCB2008_AO1465_50 VI—Pitié Salpetrière 118-08) and carried out according to the approved guidelines.

\section{Funding}

We thank Agence Nationale de la Recherche (Samenta Project I-GIVE

13-SAMA-0004-01), INSERM U940 (now U1160), U955 and AP-HP (Saint Louis Hospital and DHU PePsy).

J. Oliveira acknowledges the financial support of the Foundation for Science and Technology (Portugal) doctoral degree grant (SFRH/BD/76170/2011).

\section{Publisher's Note}

Springer Nature remains neutral with regard to jurisdictional claims in published maps and institutional affiliations.

Received: 16 May 2017 Accepted: 19 December 2017

Published online: 20 January 2018

\section{References}

American Psychiatric Association. Diagnostic and statistical manual of mental disorders. 4th ed. Paris: Masson; 1994.

Avramopoulos D, Pearce BD, McGrath J, Wolyniec P, Wang R, Eckart N, et al. Infection and inflammation in schizophrenia and bipolar disorder: a genome wide study for interactions with genetic variation. PLOS ONE. 2015;10(3):e0116696.

Bauer M, Glenn T, Pilhatsch M, Pfennig A, Whybrow PC. Gender differences in thyroid system function: relevance to bipolar disorder and its treatment. Bipolar Disord. 2014;16(1):58-71.

Bech P, Rafaelsen OJ, Kramp P, Bolwig TG. The mania rating scale: scale construction and inter-observer agreement. Neuropharmacology. 1978;17(6):430-1.

Benros ME, Eaton WW, Mortensen PB. The epidemiologic evidence linking autoimmune diseases and psychosis. Biol Psychiatry. 2014;75(4):300-6.

Berk M, Williams LJ, Jacka FN, O'Neil A, Pasco JA, Moylan S, et al. So depression is an inflammatory disease, but where does the inflammation come from? BMC Med. 2013;11:200.

Black S, Kushner I, Samols D. C-reactive protein. J Biol Chem. 2004;279(47):48487-90.

Bufalino C, Hepgul N, Aguglia E, Pariante CM. The role of immune genes in the association between depression and inflammation: a review of recent clinical studies. Brain Behav Immun. 2013;31:31-47.

Chakrabarti S. Thyroid functions and bipolar affective disorder. J Thyroid Res. 2011;2011:306367.

Dargél AA, Godin O, Kapczinski F, Kupfer DJ, Leboyer M. C-reactive protein alterations in bipolar disorder: a meta-analysis. J Clin Psychiatry. 2015;76(2):142-50.

Data-Franco J, Singh A, Popovic D, Ashton M, Berk M, Vieta E, et al. Beyond the therapeutic shackles of the monoamines: new mechanisms in bipolar disorder biology. Prog Neuropsychopharmacol Biol Psychiatry. 2017:4(72):73-86.

Dehghan A, Dupuis J, Barbalic M, Bis JC, Eiriksdottir G, Lu C, et al. Meta-analysis of genome-wide association studies in $>80,000$ subjects identifies multiple loci for C-reactive protein levels. Circulation. 2011;123(7):731-8.

Dickerson F, Stallings C, Origoni A, Boronow J, Yolken R. Elevated serum levels of $\mathrm{C}$-reactive protein are associated with mania symptoms in outpatients with bipolar disorder. Prog Neuropsychopharmacol Biol Psychiatry. 2007:31(4):952-5.

Ding K, Zhou K, He F, Shen Y. LDA—a java-based linkage disequilibrium analyzer. Bioinformatics. 2003:19(16):2147-8.

Eklund CM. Proinflammatory cytokines in CRP baseline regulation. Adv Clin Chem. 2009:48:111-36.

Ford DE, Erlinger TP. Depression and C-reactive protein in US adults: data from the Third National Health and Nutrition Examination Survey. Arch Intern Med. 2004;164(9):1010-4.

Geoffroy PA, Etain B, Scott J, Henry C, Jamain S, Leboyer M, et al. Reconsideration of bipolar disorder as a developmental disorder: importance of the time of onset. J Physiol Paris. 2013;107(4):278-85.

Gershov D, Kim S, Brot N, Elkon KB. C-Reactive protein binds to apoptotic cells, protects the cells from assembly of the terminal complement components, and sustains an antiinflammatory innate immune response: implications for systemic autoimmunity. J Exp Med. 2000;192(9):1353-64. 
Guo J, Yu L, Zhang J, Chen N, Zhou M, He L. CRP gene polymorphism predicts post-stroke functional outcome in Han Chinese. Acta Neurol Scand. 2014;129(4):263-8.

Halder I, Marsland AL, Cheong J, Muldoon MF, Ferrell RE, Manuck SB. Polymorphisms in the CRP gene moderate an association between depressive symptoms and circulating levels of C-reactive protein. Brain Behav Immun. 2010;24(1):160-7.

Hillegers MHJ, Reichart CG, Wals M, Verhulst FC, Ormel J, Nolen WA, et al. Signs of a higher prevalence of autoimmune thyroiditis in female offspring of bipolar parents. Eur Neuropsychopharmacol. 2007;17(6-7):394-9.

Hornig M, Goodman DB, Kamoun M, Amsterdam JD. Positive and negative acute phase proteins in affective subtypes. J Affect Disord. 1998;49(1):9-18.

Huang T-L, Lin F-C. High-sensitivity C-reactive protein levels in patients with major depressive disorder and bipolar mania. Prog Neuropsychopharmacol Biol Psychiatry. 2007;31(2):370-2.

Kirkpatrick B, Miller BJ. Inflammation and schizophrenia. Schizophr Bull. 2013:39(6):1174-9.

Kong H, Qian Y-S, Tang X-F, Zhang J, Gao P-J, Zhang Y, et al. C-reactive protein (CRP) gene polymorphisms, CRP levels and risk of incident essential hypertension: findings from an observational cohort of Han Chinese. Hypertens Res. 2012;35(10):1019-23.

Kupka RW, Nolen WA, Post RM, McElroy SL, Altshuler LL, Denicoff KD, et al. High rate of autoimmune thyroiditis in bipolar disorder: lack of association with lithium exposure. Biol Psychiatry. 2002;51(4):305-11.

Leboyer M, Soreca I, Scott J, Frye M, Henry C, Tamouza R, et al. Can bipolar disorder be viewed as a multi-system inflammatory disease? J Affect Disord. 2012;141(1):1-10.

Leboyer M, Oliveira J, Tamouza R, Groc L. Is it time for immunopsychiatry in psychotic disorders? Psychopharmacology. 2016;233:1651-60.

Liukkonen T, Silvennoinen-Kassinen S, Jokelainen J, Räsänen P, Leinonen M, Meyer-Rochow VB, et al. The association between C-reactive protein levels and depression: results from the northern Finland 1966 birth cohort study. Biol Psychiatry. 2006;60(8):825-30.

Martínez-Calatrava MJ, González-Sánchez JL, Martínez-Larrad MT, Pérez-Barba M, Serrano-Ríos M. Common haplotypes of the C-reactive protein gene and circulating leptin levels influence the interindividual variability in serum C-reactive protein levels. The Segovia study. Thromb Haemost. 2007;98(5):1088-95.

Maxwell ME. Manual for the family interview for genetic studies. Bethesda: $\mathrm{NIMH} ; 1992$.

Miller DT, Zee RYL, Suk Danik J, Kozlowski P, Chasman DI, Lazarus R, et al. Association of common CRP gene variants with CRP levels and cardiovascular events. Ann Hum Genet. 2005:69(Pt 6):623-38.

Montgomery SA, Asberg M. A new depression scale designed to be sensitive to change. Br J Psychiatry. 1979;134:382-9.

Nurnberger JI Jr, Blehar MC, Kaufmann CA, York-Cooler C, Simpson SG, Harkavy-Friedman J, et al. Diagnostic interview for genetic studies.
Rationale, unique features, and training. NIMH Genetics Initiative. Arch Gen Psychiatry. 1994;51(11):849-59.

Oliveira J, Hamdani N, Busson M, Etain B, Bennabi M, Amokrane K, et al. Association between toll-like receptor 2 gene diversity and early-onset bipolar disorder. J Affect Disord. 2014:165:135-41.

Ottaviani S, Gorrini M, Scabini R, Kadija Z, Paracchini E, Mariani F, et al. C reactive protein and alpha1-antitrypsin: relationship between levels and gene variants. Transl Res. 2011;157(6):332-8.

Özerdem A, Tunca Z, Çımrın D, Hıdıroğlu C, Ergör G. Female vulnerability for thyroid function abnormality in bipolar disorder: role of lithium treatment. Bipolar Disord. 2014;16(1):72-82.

Padmos RC, Bekris L, Knijff EM, Tiemeier H, Kupka RW, Cohen D, et al. A high prevalence of organ-specific autoimmunity in patients with bipolar disorder. Biol Psychiatry. 2004;56(7):476-82.

Pekny M, Wilhelmsson U, Bogestål YR, Pekna M. The role of astrocytes and complement system in neural plasticity. Int Rev Neurobiol. 2007;82:95-111.

Prins BP, Abbasi A, Wong A, Vaez A, Nolte I, Franceschini N, et al. Investigating the causal relationship of c-reactive protein with 32 complex somatic and psychiatric outcomes: a large-scale cross-consortium Mendelian randomization study. PLoS Med. 2016;13(6):e1001976.

Rahpeymai Y, Hietala MA, Wilhelmsson U, Fotheringham A, Davies I, Nilsson A-K, et al. Complement: a novel factor in basal and ischemia-induced neurogenesis. EMBO J. 2006;25(6):1364-74.

Reiner AP, Beleza S, Franceschini N, Auer PL, Robinson JG, Kooperberg C, et al. Genome-wide association and population genetic analysis of C-reactive protein in African American and Hispanic American women. Am J Hum Genet. 2012;91(3):502-12.

Rosenblat JD, McIntyre RS. Are medical comorbid conditions of bipolar disorder due to immune dysfunction? Acta Psychiatr Scand. 2015;132(3):180-91

Russell Al, Cunninghame Graham DS, Shepherd C, Roberton CA, Whittaker J, Meeks J, et al. Polymorphism at the C-reactive protein locus influences gene expression and predisposes to systemic lupus erythematosus. Hum Mol Genet. 2004;13(1):137-47.

van den Ameele S, van Diermen L, Staels W, Coppens V, Dumont G, Sabbe B, et al. The effect of mood-stabilizing drugs on cytokine levels in bipolar disorder: a systematic review. J Affect Disord. 2016;203:364-73.

Zacho J, Tybjaerg-Hansen A, Jensen JS, Grande P, Sillesen H, Nordestgaard BG. Genetically elevated C-reactive protein and ischemic vascular disease. N Engl J Med. 2008;359(18):1897-908.

Zakharyan R, Chavushyan A, Khoyetsyan A, Stahelova A, Arakelyan A, Boyajyan $A$, et al. Genetic variants of the inflammatory $C$-reactive protein and schizophrenia in Armenian population: a pilot study. Int J Immunogenet. 2010;37(5):407-10

\section{Submit your manuscript to a SpringerOpen ${ }^{\circ}$ journal and benefit from:}

- Convenient online submission

- Rigorous peer review

- Open access: articles freely available online

- High visibility within the field

Retaining the copyright to your article

Submit your next manuscript at springeropen.com 